\title{
A personagem e o espaço e o espaço da personagem: uma reflexão a partir de um corpus português
}

\author{
The character and the space and space of the character: \\ a reflection considering portuguese novels \\ Maristela Kirst de Lima Girola \\ Universidade do Vale do Rio dos Sinos - UNISINOS - Rio Grande do Sul - Brasil
} $\diamond$

\begin{abstract}
Resumo: O estudo procura demonstrar que a progressiva complexificação da construção da personagem feminina relaciona-se direta e necessariamente à construção do espaço ficcional, tomando como objetos de análise as seguintes obras: A Sibila (1954), de Agustina Bessa-Luís; O Anjo Ancorado (1958), de José Cardoso Pires; Casas Pardas (1977), de Maria Velho da Costa e Não entres tão depressa nessa noite escura (2000), de António Lobo Antunes.
\end{abstract}

Palavras-chave: Literatura Portuguesa; Romance do século XX; Espaço; Personagem

\begin{abstract}
This work demonstrates that the configuration of feminine character acquires a progressive complexity. This evolution is related directly and necessarily to the construction of fictional space. The analysis is based on novels published in the second half of twentieth century: A Sibila (1954), by Agustina Bessa-Luís; O Anjo Ancorado (1958), by José Cardoso Pires; Casas Pardas (1977), by Maria Velho da Costa and Não entres tão depressa nessa noite escura (2000), by António Lobo Antunes.
\end{abstract}

Keywords: Portuguese Literature; The Twentieth Century Novel; Space; Character

Este artigo tem como objetivo discutir a transformação da construção da personagem romanesca, ao longo da segunda metade do século XX e durante o início do século XXI, e sua estreita relação com a construção e a transformação do próprio espaço ficcional. Para demonstrar a indissociável relação que percebemos entre personagem e espaço no romance, e os novos tratamentos que essas categorias têm recebido por diferentes autores, iremos considerar um corpus português que abrange a publicação dos seguintes romances: $O$ anjo ancorado (1958) de José Cardoso Pires, A Sibila (1954) de Agustina Bessa-Luís, Casas Pardas (1977) de Maria Velho da Costa e Não entres tão depressa nessa noite escura (2000) de António Lobo Antunes.

A relação dinâmica entre sujeito e objeto, isto é, entre personagem e espaço, toma corpo, no romance, com a estética romântica, no século XIX, inaugurando uma nova concepção de espaço literário que ultrapassa a sua função de mero componente narrativo para se tornar "parte da produção imaginária de um real que é construído no texto, e se constitui como mundo em si próprio" (BUESCU, 1990, p. 79). Essa mudança se dá com a exploração sistemática da "sensação" (que tem origem no próprio corpo) em oposição ao "sentimento da natureza" (estados afetivos de caráter reflexivo e moral), como comprova Helena Buescu (1990) em sua tese, apoiada na fenomenologia da percepção desenvolvida por Maurice Merleau-Ponty.

O filósofo buscou superar o dualismo clássico entre consciência e mundo, mente e corpo, sujeito e objeto, e elaborar um "princípio unificador da individualidade mente/corpo que não fosse uma unidade de identidade, mas uma unidade e indivisibilidade do diferente, uma totalidade complexa" (SOMBRA, 2006, p. 20). Merleau-Ponty eleva a experiência perceptiva à condição de consciência perceptiva em que "consciência e subjetividade aparecem intrinsicamente ligadas à experiência humana, isto é, à percepção, ao corpo e ao mundo vivido" (SOMBRA, 2006, p. 20). A percepção é a atividade de "um corpo situado, a visão do mundo se dá a partir de um ponto de vista (nosso corpo e nossa situação) sobre o mundo" (SOMBRA, 2006, p.48). O sujeito é coextensivo à natureza, "em virtude da sensorialidade radical do corpo, a percepção é, por excelência, a relação 
do corpo com o mundo, em que um e outro coexistem sem exclusão" (SOMBRA, 2006, p. 120).

Até o século XVIII, segundo Helena Buescu (1990), predomina o sentimento da natureza que postula uma distinção entre o sujeito e o objeto, assim, ter o sentimento da natureza significa encontrar apenas dentro de si o que é necessário para a apreensão do exterior. Já a sensação na estética romântica manifesta a integração funcional do indivíduo na natureza, sendo "um meio pelo qual o sujeito pode sentir o outro (o universo) em si, e pode sentir-se a si no interior desse outro" (BUESCU, 1990, p. 86). Dessa forma, o espaço romanesco passa a ser um lugar de coexistência entre o sujeito que sente e o sensível. O espaço sendo sentido pode ser sujeito de comunicação e não somente objeto de contemplação. Isso resultará numa certa diluição do sujeito, pois se o sentimento radicava-se no interior do sujeito, "o lugar da sensação só pode ser apreendido como cruzamento, mistura (...) onde distinguir entre sujeito e paisagem/objeto não é, nem claro, nem sequer por vezes mesmo possível" (BUESCU, 1990, p. 97).

Assim, a partir da sensação, o real (paisagem) tornase agente e não apenas “"agido', o que faz repensar o lugar do sujeito perante ela" (BUESCU, 1990, p.97-98). Uma visão mais próxima do mundo torna-se possível com um sujeito que se posiciona dentro do espaço que concebe, a sua percepção é um modo de refletir sobre a constituição do mundo percepcionado, nesse sentido, o ato perceptivo é também um ato hermenêutico, ou seja, de compreensão do mundo e de seu sentido.

O romance romântico, segundo Buescu (1990, p. 88-90), teria herdado das literaturas de viagem e do romance gótico a exploração dos sentidos, especialmente o visual (descrição), que passaria para as sensações auditivas, olfativas, táteis e gustativas. O sujeito romântico acredita ser dotado de uma percepção própria do mundo, "eivada de um sentido que apenas a ele é dado perceber" (BUESCU, 1990, p. 138), o mundo para ele faz sentido, um sentido que ele constrói no interior da narrativa, não só projeta o mundo, mas o interpreta. E para o sujeito de outros períodos? Continuará a existir um sentido possível?

A ficção realista e naturalista, como se sabe, propõe, por sua vez, uma literatura de crítica do homem e da sociedade, mas sua teoria falha ao julgar possível "uma reprodução rigorosamente objetiva do mundo social que eliminasse a visão pessoal do autor", considerando "o mundo observado como coisa independente do observador" (SARAIVA; LOPES, s/d, p. 899). Os grandes romancistas realistas tiveram de vencer essa insuficiência para "não caírem na reprodução inerte, fotográfica e, no fundo, sem sentido, de casos observados", valendo-se e experimentando "pontos de vista de sucessivas personagens" (SARAIVA; LOPES, s/d, p. 900 e p. 901). A percepção do escritor organiza os dados num todo, assim como faz o pintor ao elaborar um quadro, como afirma Merleau-Ponty (2009, p. 19): "É emprestando seu corpo ao mundo que o pintor transmuta o mundo em pintura".

Em contrapartida à cosmovisão fatalista do Naturalismo, "em que o homem seria determinado, mas paradoxalmente não seria determinante", o romance neorrealista apresenta um caráter utópico de construção de um outro mundo, em que o homem se liberta do condicionamento socioeconômico para "transformar esse condicionamento pela ação (certamente revolucionária)" (TORRES, 1976, p. 28 e p. 31). A sociedade é representada em transformação por meio do que Alexandre Pinheiro Torres (1976, p. 32) define como "realismo dinâmico". Em 1976, o estudioso assinalava:

A atual fase histórica que atravessamos é, como todo e qualquer fenômeno que na natureza se observe, puramente transitória, duma transitoriedade que poderá às vezes disfarçar-se do permanente, por falta apenas de perspectiva do observador (TORRES, 1976, p. 32).

Para Torres (1976, p.33), o Neorrealismo em qualquer uma de suas fases e em qualquer um de seus representantes sempre se exercitou no campo do romance à custa de situações (...) representativas ou típicas. E por situação típica sempre se entendeu aquela que albergasse em si a latência de uma nova realidade prestes a estalar.

No que diz respeito à literatura portuguesa, entendemos que com a progressiva decadência da burguesia provinciana e a consequente derrocada dos privilégios patriarcais, a emancipação feminina passa a ser vislumbrada como uma nova realidade prestes a irromper depois de séculos de opressão. Nesse sentido, é justamente na construção das personagens femininas que podemos observar grandes mudanças na forma de representação.

José Cardoso Pires, em 1958, com O Anjo Ancorado, faz referência, já no título, à figura do "anjo", modelo tradicional, como vimos, de representação do feminino, com o qual o autor dialoga para recusar e alterar. A obra apresenta uma heroína em conflito com a sua interioridade e com o mundo à sua volta, funcionando como gérmen de uma nova mulher, que ainda não encontrou seu espaço, numa sociedade também em evolução. Guida, a protagonista, representa uma inteligência feminina isolada, que se autoanalisa, questiona-se, busca construir uma identidade por meio das palavras. Guida não se enquadra bem na imagem de mulher submissa, mas também não é uma figura revolucionária. Parece gestar uma futura mudança, anunciando já uma mulher emancipada. Contudo, é um "anjo ancorado", pois não 
alça voo, ainda de certa forma presa à figura masculina, representada pela personagem João, a quem se contrapõe.

Em $O$ Anjo Ancorado, não há propriamente uma história, mas conflitos. Guida opõe-se a João, ambos representando dois pólos de um mesmo espaço social, uma burguesia intelectualizada, que se opõe à gente simples da aldeia de São Romão. Para Torres (1964, p. 160), a obra mostra "o choque das diferentes e opostas concepções de mundo". Apesar de a história e as personagens serem situadas num tempo e num espaço precisos, o Portugal de 1957, o texto consegue "ascender à exemplaridade fabular" (TORRES, 1964, p. 160).

A obra, de cunho inovador, privilegia as personagens em relação ao enredo. Não há uma intriga nos moldes tradicionais do romance. Segundo Torres (1964, p. 153), "o desvio do centro de gravidade para a personagem constitui uma revolução na novelística", desde o início do século XX. Assim, o autor ilumina elementos antes apagados na escrita romanesca. Ao priorizar as personagens, Cardoso Pires enfatiza os valores que essas entidades representam. Por isso, o romance em questão é considerado "uma das obras fundamentais da moderna literatura portuguesa" (TORRES, 1964, p. 177).

Petar Petrov (2009), por sua vez, situa bem a prosa de estreia de Cardoso Pires que, segundo ele, compatibilizase com a visão neorrealista pelo "elevado teor de crítica de uma sociedade, espaço de injustiças e desigualdades. No entanto, a sua escrita manterá o compromisso com a realidade de uma maneira inovadora", primando pela economia narrativa, a caracterização indireta das personagens pela eleição da focalização externa e o aproveitamento da técnica cinematográfica no enfoque visual no modo de contar. A marca da escrita cardoseana em $O$ Anjo Ancorado é a subestimação da história com destaque para a personagem e não para a ação.

O romancista não se preocupa em desenvolver o espaço psicológico das personagens, antes sugere o interior a partir do exterior, por meio dos gestos, das falas e das atitudes que expõem a relação de um "eu" com o mundo. João é um desencantado da geração de 45 que se autoanalisa com ironia. Guida, da segunda geração, é marcada pela passividade de quem assiste e se interroga. As personagens são construídas pelos próprios discursos sobre si mesmas e sobre o discurso que têm sobre o outro. O caráter das personagens é formado pela exterioridade das palavras, da aparência e dos gestos. A perspectiva de Cardoso Pires não é introspectiva. Pela relação dos heróis com o espaço externo, configura-se o espaço interno ou como explica Torres (1964, p. 188):

Com evidente mestria, ele consegue tornar presente o mundo interior, não apenas pelas flutuações ou seleção dos diálogos, mas pela utilização de uma escrita metafórica, menção de um gesto, um trejeito de corpo (...) Mas só o mundo interior? Mais do que isso: o passado das personagens, toda a sua infraestrutura social. Perfeito aproveitamento dos sinais externos que sublinham o movimento da dupla eu-mundo.

Guida é o gérmen de uma nova mulher, numa sociedade machista que "não está preparada para aceitar a emancipação que nela se projeta" (TORRES, 1964, p. 196). Por isso, ela refugia-se em si mesma, ou melhor, "tenta definir-se, isto é, revelar-se" (TORRES, 1964, p.196). Não é um anjo do lar, mas um anjo que apesar de ter asas ainda não as utiliza, permanece ancorado em torno de uma figura masculina que a desdenha e com a qual procura dialogar de igual para igual. A personagem aponta para o processo de emancipação da mulher, nela já estão presentes novos valores, abrigando em si a semente de "uma transformação inelutável" (TORRES, 1964, p. 199). Contudo, sua figura é contemplativa em relação aos fatos sociais e à realidade que a cerca.

Para Nelly Novaes Coelho (2007, p. 266), Cardoso Pires, em O Anjo Ancorado,

focaliza o problema da 'nova mulher' in fieri: aquela que já não cabe na antiga imagem maniqueísta, patriarcal (rainha do lar x prostituta). Liberou-se dos limites e tabus tradicionais, passou a atuar no espaço público e a dirigir sua vida, mas ainda não encontrou sua nova imagem/verdade. Daí a perfeita metáfora criada por JCP: 'anjo ancorado' - asas impedidas de 'voar', isto é, de se realizar interiormente, no plano do Ser.

Eunice Cabral (1999, p.68 e 97), por sua vez, argumenta que, em $O$ anjo ancorado, "é pressuposta uma nova subjetividade em estado latente na personagem Guida" que "se constitui no texto entre o estatuto tradicional da rapariga burguesa e o da mulher independente, recentemente adquirido."

Em contrapartida às figuras estereotipadas de representação da mulher, Agustina Bessa-Luís, em 1954, com A Sibila, propõe uma heroína complexa que autoconstrói para si uma identidade, por meio da criação da imagem de "sibila", com a qual se insere na sociedade local de maneira respeitável e atuante. Joaquina Augusta, a protagonista, é também, ainda, uma figura feminina de transição (isso se revela pela própria alcunha da personagem: "Quina" que remete à quina (que pode designar qualquer mudança brusca na direção de uma superfície plana ou de uma linha reta), de gestação de uma futura mulher, numa sociedade marcadamente agrária e patriarcal que começa a transformar-se. Apreendemos que, naquela altura (final do século XIX e início do XX, época de vida da personagem) e naquele espaço (rural e 
rústico, em que vive), "a única forma de romper o judo do poder patriarcal, parece ser através da criação de uma identidade fora da esfera do humano" (ADÃO, 2006, p. 204).

A protagonista procura destacar-se no âmbito familiar e na sociedade, espaços dominados pela figura patriarcal, por meio da autoconstrução de uma imagem para si, a de "sibila". Outra personagem feminina importante na trama é Germana, sobrinha de Quina, que procura descobrir a sua identidade a partir das memórias familiares, num processo de autoconhecimento. Dividida entre o mundo urbano e o rural, entre os valores burgueses e os do campo, entre o passado e o presente, Germa busca, na reconstituição da trajetória da tia, um sentido para a sua própria vida.

Quina representa um elo entre as gerações femininas anteriores, subjugadas pelo masculino, e a nova geração, simbolizada por Germa, que rompe com o patriarcalismo. A "sibila" é, portanto, ainda uma figura de transição, uma "quina", uma aresta, ou seja, o "ângulo exterior formado por dois planos que se cortam" (FERREIRA, 1986, p. 161), enquanto Germa é "o gérmen, o rudimento de um novo ser" (RECTOR, 2009, p. 293).

Segundo Laura Fernanda Bulger (1990, p. 164), Germa pode ser considerada a precurssora de um ciclo de figuras femininas que têm surgido na literatura portuguesa recente, cuja busca consiste na autoanálise e no desejo de reidentificação, num ambiente perturbado e de mudança, refletindo no texto ficcional as preocupações sócio-históricas. É a protagonista multifacetada e dinâmica à volta da qual se desenvolve a narrativa e se gera uma temática que, por vezes, passa despercebida numa leitura crítica ainda pouco interessada na reabilitação literária da Mulher.

As personagens, no romance, não se definem como entidades sociais ou psicológicas nítidas, mas constituem a "manifestação simbólica (...) de uma complexidade imensa de elementos heteróclitos sobrepostos no tempo" (MACHADO, 1983, p. 189). Dessa forma, embora situadas em tempo e espaço definidos, não ficam "situadas no tempo, mesmo quando permanecem situadas no espaço" (MACHADO, 1983, p. 189).

Quina é uma heroína complexa, pois transgride o seu espaço inicial, a casa da Vessada, um espaço fechado e feminino, para transitar no espaço aberto e público, dominado pelo homem. A personagem desloca-se através da fronteira de seu campo semântico inicial. Quina viola a ordem do mundo exposto, fazendo o enredo acontecer. $\mathrm{O}$ acontecimento é sempre a violação de uma interdição, como define Lotman (1978, p. 386), "o deslocamento do herói no interior do espaço que lhe é concedido não é um acontecimento".

Em Casas Pardas (1977), Elisa, Mary e Elvira são as personagens de um livro "cujo sujeito emerge da construção de todas elas" (GUSMÃO, 1986, p.33) ou, dito de outra forma, surge da:

Reunião conflitual de vozes heterogêneas na construção de uma voz, de gestos no tecer de um corpo (...) Tudo isso constrói a voz como radicalmente intersubjetiva. Intersubjetividade como espaço de individuação da voz narrativa, das personagens, da leitura, de quem escreve e quem lê (...) intersubjetividade determinada e determinando-se social e historicamente (GUSMÃO, 1986, p. 47).

Alternando a voz narrativa entre as três personagens e mesclando os seus pontos de vista, utilizando ora a primeira, ora a segunda ou ainda a terceira pessoa do discurso, Maria Velho da Costa constrói uma subjetividade feminina complexa e multifacetada, respeitando a "natureza situacional, específica e corporizada do sujeito feminista, em detrimento de essencialismos biológicos e psicológicos" e simbolizando "a multiplicidade de variáveis que definem a subjetividade feminina: raça, classe, idade, preferências sexuais e estilos de vida, como grande eixos de definição de identidade" (BRAIDOTTI, 2002, p. 158). O recurso de variação do ponto de vista fazse presente no "olho da mosca, eficazmente poliédrico e móvel, [que] está em tudo" (COSTA, 1986, p. 381), como é colocado pelo próprio romance.

Elisa, personagem de destaque, apropria-se da língua e da cultura patriarcais para se tornar escritora e para modificar a linguagem: "Um dia hei-de escrever um livro fêmea, todo por dentro" (COSTA, 1986, p. 274). É pela escrita que construirá sua subjetividade de mulher, pois, como explica Macedo (2001, p.278):

A identidade feminina é construída na e pela linguagem (...) partindo da teorização lacaniana segundo a qual a linguagem é uma prática significativa na e pela qual o sujeito se transforma em ser social.

As características de inovação estética de Casas Pardas refletem a "necessidade de mudar as próprias formas de linguagem que, pela sua estrutura e história, tem estado sujeita a uma lei patriarcal”, além disso, "“a ação feminina' questiona e estimula a capacidade de atuação da linguagem, a sua capacidade de provocar transformações na ideologia e na economia" (MACEDO, 2001, p. 278).

Percebemos, no texto de Maria Velho da Costa, a presença de três ideias centrais de cunho feminista como a formação de uma identidade feminina a partir do corpo e da libido, a necessidade de transformação da linguagem e, finalmente, a colocação da mulher como sujeito que vê e comunica, ao invés da mulher como objeto do olhar ou do discurso. Em Casas Pardas, o diálogo com as correntes 
feministas mantém-se, bem como a referência à escrita de outras mulheres e vemos claramente a importância do corpo e da palavra para a constituição da personagem feminina: "há que aprender a manejar este feixe de coisas dúcteis mas inesperadamente ponderáveis, o corpo, que às vezes me leva o que em mim fala" (COSTA, 1986, p. 77).

A construção de uma personagem escritora, como é o caso de Elisa, apresenta a mulher como criadora e não como criatura, trazendo à tona a discussão acerca da criatividade feminina. Susan Gubar lembra-se da figura usada por Derrida para criticar o falocentrismo no processo literário, isto é, a identificação da pena com o pênis: "Este modelo da pena/pênis que escreve sobre a folha virgem participa numa longa tradição que identifica o autor como masculino que é primário e o feminino como sendo a sua criação passiva" (GUBAR, 2002, p. 102). Essa tradição que deixa a mulher de fora "da produção da cultura, ao mesmo tempo que a reifica como artefato cultural, é obviamente problemática para as mulheres que querem apropriar-se da pena, tornando-se escritoras" (GUBAR, 2002, p. 102).

A personagem Elisa rompe com essa tradição, apropria-se da pena masculina, da intelectualidade que herdou do pai e planeja para o futuro matricular-se na universidade, "ratificou a sua intenção de matricular-se na universidade, fazer estudos sérios e imiscuir-se na vida de coletivos muito grandes, estando lá, Sempre é um princípio" (COSTA, 1986, p. 380) e escrever, "achava Elisa que entenderia escrevendo" (COSTA, 1986, p. 381), inaugurando um novo tipo feminino.

A leitura e a escrita constituem-se, no romance, em estratégias de resistência à perspectiva masculina apresentada como sinônimo de perspectiva humana. Como alerta Jonathan Culler (1997, p.60), "ler como uma mulher não é, necessariamente, o que acontece quando uma mulher lê: mulheres podem ler, e leram como homens". Ler como uma mulher não implica em uma condição biológica, mas numa posição política, numa maneira de apontar o que o falocentrismo esconde. Assim, como bem sintetiza Culler (1997, p. 74), “'mulher' passou a significar qualquer força radical que subverta os conceitos, suposições e estruturas do tradicional discurso masculino". O espaço da escrita torna-se o espaço de construção de uma subjetividade que desafia a tradição literária falogocêntrica, resultando em textos que não seguem as regras da literatura convencional.

Maria Clara de Não entres tão depressa nessa noite escura, de António Lobo Antunes, assemelha-se a Elisa de Casas Pardas na questão da criatividade, ambas questionam o seu ser no mundo por meio da atividade de escrita. Não são configuradas, antes se configuram e configuram o mundo através das palavras. No título do romance de Lobo Antunes, temos a referência à noite "enquanto tempo propiciador de uma solidão essencial à criatividade, se apresenta como o lugar de confronto do eu com seus fantasmas" (SANTOS, 2005, p. 17).

Elisa (Casas Pardas) e Maria Clara (Não entres tão depressa nessa noite escura), como personagens escritoras, apropriam-se da língua e da escolaridade patriarcais para fundar uma nova escrita, por meio da "valorização da linguagem e consequentemente da representação, como o local da constituição do sujeito" (BRAIDOTTI, 2002, p. 152). O espaço da escrita torna-se o espaço de construção de uma subjetividade que desafia a tradição literária falogocêntrica, resultando em textos que não seguem as regras da literatura convencional.

Ann Rosalind Jones (2002, p.77) defende uma resistência que se "manifesta na joissance, isto é, na reexperiência direta dos prazeres físicos da infância e mais tarde da sexualidade, reprimida mas não obliterada pela Lei do Pai”. Essa reexperiência ocorre por meio da instauração de um novo discurso, um discurso de "mulher", em que "mulher" representa não um sexo, mas uma atitude antifalogocêntrica, possível também para os homens. Nesse sentido, reconhecemos, no romance de Lobo Antunes, o mesmo caráter de resistência ao falogocentrismo literário que percebemos em Maria Velho da Costa, pelo trabalho inovador de linguagem que ambos executam, construindo textos que desafiam as normas e a regularidade da língua convencional.

A resistência à visão e à linguagem monolíticas patriarcais faz-se presente nos dois autores, não só pelo trabalho peculiar de linguagem, mas também pela temática e valores que abordam em seus romances, em que vemos a discordância em relação à valorização da violência masculina, típica de uma visão patriarcal do mundo. Segundo Maria Alzira Seixo (2008, v. II, p. 416), na obra de Lobo Antunes, por exemplo, há uma "mundividência de caráter ideológico" em que se percebem "antissalazarismo e anticolonialismo, antibelicismo, atenção ao sofrimento dos indivíduos e suas carências e desfavorecimentos".

Gostaríamos de ressaltar, uma vez mais, que acreditamos ser possível identificar, no texto dos autores, o conceito de écriture féminine, se entendido no sentido proposto por Elaine Showalter (2002, p.46-47), isto é, como "textualidade da vanguarda, uma produção literária dos finais do século XX, (...) uma esperança, senão um modelo, para o futuro". Maria Velho da Costa e Lobo Antunes desconstroem o "pai", a estrutura tradicional do romance, buscando refutar a velha visão patriarcal de mundo, lutando contra "a comunicação perfeita, contra o único código que traduz todo o significado com perfeição, o dogma central do falogocentrismo" (HARAWAY, 2002, p.246).

Os dois autores, em nossa opinião, constituem-se em expoentes de uma mudança literária profunda, na 
literatura portuguesa da segunda metade do século XX, constatada por historiadores como Saraiva e Lopes (s/d, p. 1097):

As liberdades de expressão e as mudanças sociais obtidas através do movimento de 25 de abril de 1974 apenas cerca de 1980 se fizeram sentir numa nova promoção de escritores, depois da edição de obras anteriormente censuradas e de uma genérica evolução dos já consagrados (...) os efeitos mais importantes no terreno literário manifestam-se, de início, sob a forma de novas inflexões (...) a propósito de duas tendências que vêm acentuar-se desde os anos 50 e 60, uma social e outra mais especificamente literária (...) estreitamente ligadas: a tendência de emancipação feminina, que ainda em geral se implanta na experiência das camadas médias; e a tendência para transformações mais ou menos radicais da própria ficção narrativa, em correspondência com uma profunda crise de concepção de vida que questiona as tradicionais categorias da novelística (enredo, caracteres, efeito do real, coerência de concepção de vida ou de estrutura).

Seixo (1984, p. 31) entende o ano de 1974 como um divisor na história da literatura portuguesa, pois

após um ano escasso de produção romanesca (o próprio ano de 1974), os ímpetos de escrita começaram justamente a multiplicar-se, materializando-se na edição genericamente a partir de três vetores: o da produção regular de autores já consagrados, o do surgimento de personalidades literárias que durante este período se manifestam e afirmam, o da revelação de novos ficcionistas que cultivam por enquanto as suas primeiras experiências.

Ainda de acordo com Seixo (1984, p. 32), o romance do período em que se situa Casas Pardas, ou seja, a segunda parte dos anos 70 ,

vai sobretudo proceder a uma miscigenação de modos numa proposta de abertura descondicionada e indisciplinada que conduz a uma euforia de escrita muito produtiva mas de efeitos desiguais. Adquire um peso teórico-prático impressionante a noção de 'escrita', e como 'textos' (encarados enquanto urdiduras de escrita) se consideram a maior parte das obras que então vêm a lume.

Essas características acentuam-se na década de 80, quando um novo discurso passa a consolidar-se:

se os anos cinquenta e sessenta foram já sensíveis a uma pluralidade de nivelamentos narrativos e ao relativismo temporal e subjetivo que lhe é condicionante, só estes últimos anos vêem constituir-se com evidência um novo discurso onde é justamente no plano da linguagem ou na articulação dos níveis efabulativos que a referida pluralidade se tenta (SEIXO, 1984, p.37).
Salientamos ainda que Maria Velho da Costa e António Lobo Antunes são autores cujos textos exigem uma participação ativa dos leitores. Desacomodando-os, procuram fazer do leitor "não mais um consumidor, mas o produtor do texto" e o romance torna-se, muitas vezes, uma batalha "contra as expectativas romanescas convencionais dos leitores e em sua ruptura com os processos habituais de produção de sentido" (CULLER, 1997, p.47). Em Não entres tão depressa nessa noite escura, o leitor sente-se interpelado já pelo próprio título e encontra uma "escrita de imprecação (manifestação de rebeldia ou mesmo revolta do narrador) que provoca o leitor" (SEIXO, 2008, v. I, p. 146).

Casas Pardas e Não entres tão depressa nessa noite escura são exemplos de transformação do romance em correspondência com uma profunda crise de concepção da vida e do mundo, por meio do questionamento das próprias categorias narrativas. Embora reconheça, simultaneamente, no texto de Maria Velho da Costa um trabalho de desconstrução do tradicional e uma "construidíssima teia de sentidos" (SEIXO, 1979, p. 91), é em Lobo Antunes, a partir da publicação de Não entres tão depressa nessa noite escura, que Seixo identifica o traço da pós-modernidade

pela criação de efeitos de indecibilidade no plano da intriga, da caracterização dúplice ou mesmo falsa de personagens, e de uma organização frásica que se desmembra, anexando a incidência lírica que liberta o texto da conformação ao gênero, cuja desconstrução o pós-moderno sistematicamente pratica. No fundamental, os romances de Lobo Antunes reencontram-se sempre com uma história contada, e até movimentada e cheia de peripécias (no que dialoga com o modelo novecentista do gênero, e essa é uma vertente, de neoclassicismo paródico, do pós-moderno), sendo a sua narração que de certo modo a apaga, submetendo-a à passividade da escrita subjetiva (da voz personalizada) que encobre o tumulto do mundo para o tornar texto (SEIXO, 2008, v. II, p. 237).

A forma de construção do espaço ficcional é a marca de inovação que se inaugura na escrita de Não entres tão depressa nessa noite escura, mantendo-se em romances posteriores:

Na prática da composição do texto, numa dinâmica quase caleidoscópica da montagem de lugares diversos, que por vezes se sucedem vertiginosamente (vários num mesmo capítulo, nos romances mais recentes, vários por vezes na mesma frase - e o romance que pratica esta forma esplendorosa de montagem espacial alucinante, ou alucinada, é Não entres tão depressa nessa noite escura (SEIXO, 2008, v. II, p. 354). 
Esse modo de construção do espaço consiste numa espacialização sugerida (como extensão territorial e como lugar de significação interior), fortemente temporalizada (...) que, sobretudo a partir de Não entres tão depressa nessa noite escura (...) tornam a sua obra também numa espécie de 'novo romance' (SEIXO, 2008, v. II, p. 230).

Em Não entres tão depressa nessa noite escura, portanto, constatamos a complexificação da construção do espaço ficcional em correspondência com a complexificação da construção da personagem feminina, tornada em subjetividade instauradora desse universo de escrita. Maria Clara é uma mulher sujeito, ou melhor, é um ser humano com toda a sua idiossincrasia. É espaço e "consciência monologante", é a voz que transforma o mundo em texto e "o livro [que] fica sendo uma parte (insubmissa) desse mundo" (SEIXO, 2008, v. II, p.236 e 238). Seu corpo é a escrita, pois a "instância física" ou

a expressão corpórea da personagem, quer feminina, quer masculina é, para além de sinônimo de insignificância reincidente, um mapa indicativo de traumas, desencontros, desamores, (...) conjugalidades distraídas. (SEIXO, 2008, v. II, p. 175).

Se em Guida de $O$ Anjo Ancorado reconhecemos a mulher que experimenta a sua voz; se em Germa de A Sibila identificamos a mulher guardiã da memória e narradora de histórias; se em Elisa de Casas Pardas encontramos o nascimento da mulher escritora, em direção a "um caminho ainda incerto, ainda desconhecido: o ensaio dos textos" (SEIXO, 2008, v. II, p. 91), em Maria Clara, de Não entres tão depressa nessa noite escura, verificamos a mulher escritora em pleno domínio da tecedura narrativa, consciente do jogo que joga, entre a vida e a ficção, naquilo que silencia, naquilo que revela, naquilo que inventa "com papel decisivo nas matérias que seleciona ou cala, e nas alterações - simulações, mentiras - que na sua narração inclui" (SEIXO, 2008, v. II, p. 149). Como sintetiza Seixo (2008, v. II, p. 149), Maria Clara realiza "o objetivo de inventar a verdade". Essa personagem mostra-nos o romance não como "a escrita de um acontecimento", mas como o "acontecimento da escrita" (SEIXO, 2008, v. II, p. 232) no qual a mulher é finalmente autor e partícipe.

Não entres tão depressa nessa noite escura, de António Lobo Antunes, privilegia a personagem e sua problemática, o que se descortina para o leitor não é propriamente uma história, mas um espaço ficcional que se confunde com a própria heroína em construção. De acordo com Seixo (2011, p.243), "Maria Clara não conta uma história; ela defronta-se com um enigma, que (...) poderemos considerar como sendo o de si própria perante os outros." Em um momento de fusão de vozes, entende-se que Maria Clara é todas as personagens em que se fragmenta, uma identidade múltipla, um ser multifacetado: "Conhecendo-nos, tu és esta, tu és aquela, tu és aqueloutra, não julguem que não sei quem são, tu por exemplo és a Maria Clara sou a Maria Clara" (ANTUNES, 2000, p. 521). A narrativa desnuda um "eu", sendo centrada no sujeito, núcleo de um espaço vital. Esse sujeito é objeto do próprio discurso, o "eu" é sujeito e objeto, narra e age: "escrevo uma linha ou duas, apago, torno a escrever a não foi assim" (ANTUNES, 2000, p. 467).

O foco central do romance, como constatamos, é a vida da personagem Maria Clara, um "eu" que se fragmenta em outros "eus". Essa fragmentação do sujeito que escreve se inscreve num processo de despersonalização que, conforme Catherine Dumas (1994), encontra-se no centro da escrita intimista em geral. No romance antuniano, portanto, o que prepondera é a desagregação do espaço e do sujeito, decorrente da fragmentação. O sujeito que lê também desempenha papel fundamental na construção do discurso memorialista do autor, como bem explica Felipe Cammaert Hurtado (2004, p. 297):

Na medida em que a obra questiona a memória e desvela o vasto espaço da subjetividade das personagens, ele [o leitor] intui desde o princípio que a sua participação é essencial para aperfeiçoamento do romance.

O crítico considera a memória "o princípio organizativo" (HURTADO, 2004, p. 299) dos textos de Lobo Antunes, "o eixo central" de sua narrativa e "um dos pilares do universo antuniano" (HURTADO, 2004, p.298). Mais do que uma temática, a memória apresenta-se como um estilo:

Todas as histórias são fundadas nas lembranças das personagens; a narração irrompe sob a forma de uma catarse, por vezes caótica mas sempre abundante em imagens poéticas (HURTADO, 2004, p. 298-299).

Vemos em todos os romances analisados ao longo deste artigo, a prevalência da personagem em relação ao enredo, sendo Casas Pardas e Não entres tão depressa nessa noite escura, entre os textos do corpus selecionado, os exemplos mais extremos dessa tendência que irá se estender ao início do século XXI. Acrescentaríamos que à importância da personagem na narrativa soma-se a importância, simultânea, do espaço ficcional (mundo do texto) em que ambas as instâncias não são mais de todo "separáveis" ("distinguir entre sujeito e paisagem/ objeto não é, nem claro, nem sequer por vezes mesmo possível", cf. BUESCU, 1990), numa relação cada vez 
mais dinâmica, desde o Romantismo, entre sujeito e objeto, entre personagem e espaço (categoria cada vez mais distante da ideia de mero cenário).

O espaço (o mundo) é parte integrante da própria noção de sujeito. Portanto, podemos afirmar que a complexificação da construção da personagem feminina, no romance português, relaciona-se direta e necessariamente à construção do espaço ficcional. Como já assinalara Buescu (1990), o espaço literário ou a forma de concebê-lo não é imutável, mas passível de mutações, de acordo com as alterações na maneira do ser humano pensar a si próprio, sendo, ao mesmo tempo, o elemento organizador do espaço e parte integrante dele. O romance, desde o século XIX, pode ser considerado como lugar privilegiado para se pensar sobre o espaço como passível de mutações estéticas decorrentes das transformações na forma do ser humano refletir sobre si mesmo e sobre o mundo. Nesse sentido, torna-se fundamental a ideia de "ponto de vista", pois a ela ligam-se necessariamente as diferentes apreensões do espaço. A possibilidade de se adotar pontos de vista variáveis diz respeito à configuração da narrativa, especialmente, no que tange ao plano espacial.

Os conflitos entre as personagens (e o consequente desencadeamento do tema), segundo Lotman (1978), consistem em um simultâneo choque entre as suas ideias acerca do mundo. Como bem explicitam Paul Ricoeur (1995) e Buescu (1990), o ponto de vista pode coincidir com o narrador ou com outras personagens, definindo o texto em sua globalidade, em suas várias instâncias.

A possibilidade de adotar pontos de vista variáveis diz respeito à configuração da narrativa e, muito especialmente, ao plano espacial, uma vez que "é de início a perspectiva espacial, considerada literalmente, que serve de metáfora para todas as outras expressões do ponto de vista" (RICOEUR, 1995, p. 156). O conceito de ponto de vista pressupõe a noção de percepção, o que implica em "posição, ângulo de abertura, profundidade de campo", em outras palavras, "o ponto de vista pode ser definido (...) como lugar de origem, orientação, ângulo de abertura de uma fonte de luz que, ao mesmo tempo, ilumina seu tema e capta seus traços" (RICOEUR, 1995, p. 156 e p. 158).

A noção de ponto de vista liga-se ao conceito de percepção, que é a atividade de um corpo situado. A visão e o entendimento do mundo dão-se a partir de um ponto de vista, de um corpo e de uma situação sobre o mundo. A subjetividade, assim, aparece relacionada à experiência humana, como assinala Merleau-Ponty. O sujeito é coextensivo ao mundo, sendo a percepção a relação do corpo com o mundo. O espaço romanesco passa a ser entendido, a partir da estética romântica, como lugar de coexistência entre o sujeito que sente e o sensível, o que resulta em certa diluição do sujeito e explica a importância súbita que a paisagem assume no romance, como esclarece Buescu (1990), deixando de consistir em mero pano de fundo da intriga. Mundo e sujeito coexistem sem exclusão possível.

Para verificar a construção da personagem feminina como sujeito, no romance português, foi preciso analisar, portanto, a configuração do espaço ficcional, como parte integrante dessa transformação.

A voz e o olhar que estruturavam a narrativa, construindo o espaço ficcional, eram predominantemente masculinos. Mesmo quando individualizada, a personagem feminina não escapava a uma perspectiva patriarcal de mundo a que se encontrava submetida. Nos romances da segunda metade do século, como vimos, começa a surgir um novo tipo de representação do feminino, pois a personagem feminina passa a figurar de maneira mais independente em relação à personagem masculina. Sua construção complexifica-se (com aprofundamento psicológico e ganho de poder discursivo), angariando uma importância funcional maior no espaço romanesco.

Percebemos que há, concomitantemente, um avanço inovador entre a reestruturação do espaço ficcional do romance e a construção da personagem feminina que adquire um estatuto pleno, dotada de voz e de visão própria do mundo. Entre os romances analisados, destacamos Casas Pardas e Não entres tão depressa nessa noite escura como os mais agudos exemplos dos resultados estéticos dessa transformação, uma vez que, nesses romances, as heroínas protagonizam uma mudança no tratamento da linguagem e na narração/configuração do espaço ficcional romanesco, livres de uma ótica/lógica falogocêntrica, restrita e condicional.

É também em Casas Pardas e em Não entres tão depressa nessa noite escura que vemos a personagem feminina surgir como a grande (des)configuradora do espaço, como a narradora-escritora do próprio livro que se lê, como a subjetividade problematizadora da complexidade do mundo. Esse percurso fôra iniciado por Cardoso Pires ao recusar a visão patriarcal de mundo, desvinculando as suas heroínas do espaço doméstico e por Bessa-Luís com a imagem das mulheres contadoras de histórias (como Quina, Germa e suas antepassadas), e agora as vemos às voltas com a pena (por tanto tempo exclusiva dos homens), em pleno domínio das letras. Adentrando no universo literário, antes espaço dos homens, situam-se, literalmente, dentro da representação textual do mundo (o mundo do texto) para pensar-se dentro dele e em relação a ele. Dessa forma, alteram para sempre a escrita do mundo e o mundo da escrita. 


\section{Referências}

ADÃO, Deolinda M. Novos espaços do feminino: uma leitura de Ventos do apocalipse de Paulina Chiziane. In: A mulher em África: vozes de uma margem sempre presente. Lisboa: Colibri/ Centro de Estudos Africanos-FLUL, 2006.

BUESCU, Helena Carvalhão. Incidências do olhar: percepção e representação. Natureza e registo descritivo na evolução do romance romântico (Portugal, França, Inglaterra). Lisboa: Caminho, 1990.

ANTUNES, António Lobo. Não entres tão depressa nessa noite escura. Lisboa: Dom Quixote, 2000.

BRAIDOTTI, Rosi. A diferença sexual como um projecto político nómada. Trad. Joana Passos. In: MACEDO, Ana Gabriela (Org.). Gênero, identidade e desejo: antologia crítica do feminismo contemporâneo. Lisboa: Cotovia, 2002.

BULGER, Laura Fernanda. A Sibila - uma superação inconclusa. Lisboa: Guimarães, 1990.

CABRAL, Eunice. José Cardoso Pires: representações do mundo social na ficção (1958-82). Lisboa: Cosmos, 1999.

COELHO, Nelly Novaes. Escritores portugueses do século $X X$. Lisboa: Imprensa Nacional-Casa da Moeda, 2007.

COSTA, Maria Velho da. Casas Pardas. 3. ed. Lisboa: Dom Quixote, 1986.

CULLER, Jonathan D. Sobre a desconstrução: teoria e crítica do pós-estruturalismo. Tradução de Patrícia Burrowes. Rio de Janeiro: Record; Rosa dos Tempos, 1997.

FERREIRA, Aurélio Buarque de Holanda. Novo dicionário da Lingua Portuguesa. 2. ed. Rio de Janeiro: Nova Fronteira, 1986.

GUBAR, Susan. A "página em branco" e questões acerca da criatividade feminina. Tradução de Francesca Rayner. In: MACEDO, Ana Gabriela (Org.). Gênero, identidade e desejo: Antologia crítica do feminismo contemporâneo. Lisboa: Cotovia, 2002.

GUSMÃO, Manuel. Casas Pardas - a arte da polifonia e o rigor da paixão: uma poética da individuação histórica. In: COSTA, Maria Velho da. Casas Pardas. 3. ed. Lisboa: Dom Quixote, 1986.

HARAWAY, Donna. O manifesto ciborgue: a ciência, a tecnologia e o feminismo socialista nos finais do século XX. Tradução de Ana Maria Chaves. In: MACEDO, Ana Gabriela (Org.). Gênero, identidade e desejo: Antologia crítica do feminismo contemporâneo. Lisboa: Cotovia, 2002.

HURTADO, Felipe Cammaert. O leitor da memória: o papel do leitor em $O$ manual dos inquisidores. In: CABRAL, Eunice; JORGE, Carlos J. F.; ZURBACH, Christine (Org.). A escrita e o mundo em António Lobo Antunes. Actas do Colóquio Internacional da Universidade de Évora. Lisboa: Dom Quixote, 2004.

JONES, Ann Rosalind. Escrever o corpo: para uma compreensão de l'écriture féminine. Tradução de Maria Filomena Louro. In: MACEDO, Ana Gabriela (Org.). Gênero, identidade e desejo: Antologia crítica do feminismo contemporâneo. Lisboa: Cotovia, 2002.

LOTMAN, Iuri. A estrutura do texto artístico. Trad. Maria do Carmo Vieira Raposo e Alberto Raposo. Lisboa: Estampa, 1978.
MACEDO, Ana Gabriela. Os estudos feministas revisitados: finalmente visíveis? In: BUESCU, Helena Carvalhão; DUARTE, João Ferreira; GUSMÃO, Manuel (Org.). Floresta encantada: novos caminhos da literatura comparada. Lisboa: Dom Quixote, 2001.

MACHADO, Álvaro Manuel. Agustina Bessa-Luís: o imaginário total. Lisboa: Dom Quixote, 1983.

MERLEAU-PONTY, Maurice. O olho e o espírito. 7. ed. Trad. Luís Manuel Bernardo. Lisboa: Veja, 2009.

PETROV, Petar. O ensaio na obra de José Cardoso Pires. Disponível em: <http:victorian.fortunecity.com/statue/44/ Oensaionaobradejosecardoso.html>. Acesso em: 18 set. 2009.

RECTOR, Mónica. A voz da Sibila. In: LEÃO, Isabel Ponce (Org.). Estudos Agustinianos. Porto: Universidade Fernando Pessoa, 2009.

RICOEUR, Paul. Tempo e narrativa. Trad. de Marina Appenzeller. Campinas: Papirus, 1995. Tomo II.

SANTOS, Inês Fonseca. Pelas veredas da infância: o regresso a casa num poema de Manuel António Pina. In: Textos e Pretextos, Lisboa, Centro de Estudos Comparatistas, Faculdade de Letras, Universidade de Lisboa, As Casas, n. 6, 2005.

SARAIVA, Antônio José. LOPES, Óscar. História da literatura portuguesa. 4. ed. Porto: Porto, s/d.

SEIXO, Maria Alzira. Dez anos de literatura portuguesa (1974-1984): ficção. In: Colóquio/Letras. Balanço, n. 78, p. 30-42, mar. 1984 .

SEIXO, Maria Alzira (Org.). Dicionário da obra de António Lobo Antunes. Lisboa: Imprensa Nacional-Casa da Moeda, 2008. Vol. I.

SEIXO, Maria Alzira (Org.). Dicionário da obra de António Lobo Antunes. Lisboa: Imprensa Nacional-Casa da Moeda, 2008. Vol. II.

SEIXO, Maria Alzira. Maria Velho da Costa - Casas Pardas. In: Colóquio/Letras, Balanço, n. 47, p. 90-91, jan. 1979.

SEIXO, Maria Alzira. O livro da criação. In: ARNAUT, Ana Paula. António Lobo Antunes: a crítica na imprensa. 1980-2010. Cada um voa como quer. Coimbra: Almedina, 2011. p. 243.

SHOWALTER, Elaine. A crítica feminista no deserto. Trad. de Margarida Esteves Pereira. In: MACEDO, Ana Gabriela (Org.). Gênero, identidade e desejo: antologia crítica do feminismo contemporâneo. Lisboa: Cotovia, 2002.

SOMBRA, José de Carvalho. A subjetividade corpórea: a naturalização da subjetividade na filosofia de Merleau-Ponty. São Paulo: UNESP, 2006.

TORRES, Alexandre Pinheiro. O neo-realismo literário português. Lisboa: Moraes, 1976.

TORRES, Alexandre Pinheiro. Sociologia e significado do mundo romanesco de José Cardoso Pires: um ensaio de interpretação expressamente dedicado ao Leitor Distraído. In: O Anjo Ancorado. 3. ed. Lisboa: Arcádia, 1964.

Recebido: 17/11/2016

Aprovado: 13/03/2017

Contato: maristela.klg@gmail.com 